\title{
CARACTERIZAÇÃO MORFOMÉTRICA DA MICROBACIA HIDROGRÁFICA DO CÓRREGO DA FAZENDA GLÓRIA, MUNICÍPIO DE TAQUARITINGA, SP.
}

\author{
Flavia Mazzer Rodrigues ${ }^{1}$; Teresa Cristina Tarlé Pissarra ${ }^{1}$; Sérgio Campos ${ }^{2}$ \\ ${ }^{I}$ Departamento de Engenharia Rural, Faculdade de Ciências Agronômicas e Veterinária, Universidade Estadual \\ Paulista,Jaboticabal,SP,flamazzer@hotmail.com \\ ${ }^{2}$ Departamento de Engenharia Rural, Faculdade de Ciências Agronômicas, Universidade Estadual Paulista, \\ Botucatu, SP
}

\section{RESUMO}

Com a análise das características morfométricas, procura-se entender a relação solosuperfície, em decorrência dos processos erosivos sobre estruturas e litologias variadas. Neste trabalho, objetivou-se caracterizar, no período de 1983 e 2000, as características morfométricas na Microbacia Hidrográfica do Córrego da Fazenda Glória, de $4^{\mathrm{a}}$ ordem de magnitude, Município de Taquaritinga - SP. Esta microbacia hidrográfica foi dividida em 7 microbacias hidrográficas de $2^{\mathrm{a}}$ ordem e 2 microbacias hidrográficas de $3^{\mathrm{a}}$ ordem. As características morfométricas demonstraram que ocorreu uma redução do número de segmentos de rios de 1. ${ }^{a}$ ordem e comprimento da rede de drenagem ao longo do período analisado, estando relacionadas às diversas influências que a evolução do modelado sofreu, tendo em vista o uso e ocupação do solo, indicando comportamento hidrológico desigual. Os resultados permitiram inferir que o comprimento do segmento de rio de $4^{\mathrm{a}}$ ordem se manteve constante ao longo do período analisado.

UNITERMOS: sensoriamento remoto, análise morfométrica, microbacias hidrográficas.

\section{RODRIGUES, F. M.; PISSARRA, T. C. T.; CAMPOS, S. MORPHOMETRIC CHARACTERIZATION OF GLÓRIA FARM WATERSHED, TAQUARITINGA, STATE OF SÃO PAULO, BRAZIL.}

\section{ABSTRACT}

The analysis of morphometric characteristics is used to understand the relationship between soil and surface as a result of erosive processes on different structures and lithologies. The objective of this study was to study the morphometric characteristics of Fazenda Gloria watershed from 1983 to 2000, a fourth-order watershed in Taquaritinga Municipality, São Paulo State. The study was based on photointerpretation techniques. Drainage net and the respective watersheds were selected and the morphometric variables were determined. The watersheds consisted of 7 second-order watersheds and 2 third-order watersheds. The morphometric characteristics showed a reduction in the number of segments of first-order rivers and in the length of the drainage net during the study period. These findings could be related to several influences on land development considering the occupation and use of land. A different hydrological behavior could also be observed. The analysis of Fazenda Glória Watershed showed that the length of the segment of fourth order river remained constant during the study period. 
KEY WORDS: remote sensing, morphometric analysis, watershed.

\section{INTRODUÇÃO}

O termo bacia hidrográfica pode ser definido como a área de captação natural da água de precipitação, a qual drena a água por ravinas, canais e tributários, para um curso d'água principal, e tem a vazão numa saída, que deságua em um curso d'água maior, lago ou oceano. A bacia hidrográfica deve ser considerada como uma unidade de trabalho quando se deseja a preservação dos recursos hídricos, já que as atividades desenvolvidas no seu interior têm influência sobre a quantidade e qualidade da água. Constitui-se na mais adequada unidade de planejamento para o uso e exploração dos recursos naturais, pois seus limites são imutáveis dentro do horizonte de planejamento humano, o que facilita o acompanhamento das alterações naturais ou introduzidas pelo homem na área.

As características físicas de uma bacia possuem importante papel nos processos do ciclo hidrológico, influenciando, dentre outros, a infiltração, a quantidade de água produzida como deflúvio, a evapotranspiração, o escoamento superficial e subsuperficial.

A remoção da vegetação em um ambiente florestal leva, conseqüentemente, a processos erosivos, que geram degradação do ambiente, e podem se propagar para áreas adjacentes. Assim, a declividade e a cobertura vegetal tornam-se fatores importantes na tomada de decisão de um manejo adequado da bacia hidrográfica, visto que influenciam a precipitação efetiva, escoamento superficial e fluxo de água no solo, dentre outros, (Cardoso et al. 2006).

A bacia hidrográfica, como sistema aberto, pode ser descrita em termos de variáveis interdependentes, as quais oscilam ao longo de um padrão ou de uma média. Como tal, ela se encontra, mesmo quando não perturbada, em contínua flutuação, num estado de equilíbrio transacional ou dinâmico. Ou seja, a adição de energia e a perda de energia do próprio ecossistema encontram-se sempre em delicado balanço (Lima, 1986),

Desse modo, a área da bacia hidrográfica tem influência sobre a quantidade de água produzida como deflúvio. A forma e o relevo, por outro lado, atuam sobre a taxa, ou sobre o regime desta produção de água, assim como a taxa de sedimentação. O caráter e a extensão dos canais (padrão de drenagem) afetam a disponibilidade de sedimentos, bem como a taxa de formação do deflúvio. Muitas destas características físicas da bacia hidrográfica, por sua vez, são em grande parte controladas ou influenciadas pela sua estrutura geológica (Pissarra, 2002).

As características morfométricas do padrão de drenagem e do relevo refletem algumas propriedades do terreno, como infiltração e deflúvio das águas das chuvas, e expressam estreita correlação com a litologia, estrutura geológica e formação superficial dos elementos que compõem a superfície terrestre. Portanto, estão entre as classes de informações morfológicas que determinam diferenças essenciais entre distintas paisagens, como relatam estudos clássicos desenvolvidos por Horton (1945), Strahler (1957), França (1968) e Christofoletti (1978).

Uma proposta metodológica muito bem estruturada que deu um grande impulso no desenvolvimento da análise morfométrica dos sistemas naturais de drenagem foi apresentada por Horton (1945). O estudo de Horton (1945), a quem cabe a primazia de efetuar a interpretação quantitativa das bacias hidrográficas, veio marcar o ponto de partida para uma nova fase da morfometria, através da proposição de inúmeros aspectos de abordagem analítica para os cursos d'água. 
A metodologia de Horton também contribuiu com um novo sistema de classificação baseado na ordem de magnitude de cada canal ou segmento de rio que forma a rede de drenagem. Pelo critério de classificação desse sistema, foi possível eliminar algumas limitações do sistema até então adotado, o sistema europeu, proposto por Gravelius. O novo sistema facilitou o emprego de procedimentos matemáticos na análise do sistema natural de drenagem. Além dessa contribuição muito significativa, esse autor propôs diversos índices quantitativos para o sistema de drenagem e relacionou-os com as condições hidrológicas.

Em estudos das interações entre os processos, sob o ponto de vista quantitativo, utiliza-se o método de análise morfométrica através dos seguintes parâmetros: densidade de drenagem, coeficiente de compacidade, índice de circularidade, forma da bacia, dentre outros. Estes parâmetros podem revelar indicadores físicos específicos para um determinado local, de forma a qualificarem as alterações ambientais (Alves \& Castro, 2003).

Christofoletti et al.(1993) diz que os processos de desenvolvimento e ocupação do espaço pela atividade humana tem desencadeado uma necessidade crescente de estudos de elementos da paisagem que subsidiem a elaboração de planos ordenadores na relação homem/natureza, a fim de ser minimizada a degradação ambiental.

Guerra \& Guerra (2003) definem, resumidamente, a morfometria como sendo o estudo quantitativo das formas de relevo. Cabe lembrar que nenhum desses índices isoladamente deve ser entendido como capaz de simplificar a complexa dinâmica da bacia a qual, inclusive, tem magnitude temporal.

Nesse contexto, o objetivo deste trabalho compreendeu o estudo da morfometria da microbacia hidrográfica da Fazenda Glória, localizada no município de Taquaritinga, SP, para tornar possível o manejo integrado de seus recursos naturais.

\section{MATERIAL E MÉTODOS}

A área de estudo, localiza-se no Município de Taquaritinga - SP; na parte centro norte do Estado de São Paulo do planalto ocidental paulista. Com uma área de 2039,32ha, situa-se entre as coordenadas geográficas: latitudes $21^{\circ} 18^{\prime} 23^{\prime \prime} \mathrm{S}$ e $21^{\circ} 22^{\prime} 32^{\prime \prime} \mathrm{S}$ e longitudes $48^{\circ} 27^{\prime}$ 54 " e $48^{\circ} 31^{\prime} 51^{\prime \prime}$ WGr.

O Município de Taquaritinga (Figura 1) é servido pelas rodovias estaduais Carlos Tonanni (SP 333), Washington Luiz (SP 310) e Anhanguera (SP 330). O Município possui como Municípios circunvizinhos, Monte Alto, Guariba, Jaboticabal, Santa Ernestina, Dobrada, Matão, Itápolis e Cândido Rodrigues e é ladeado pelas Serras do Jaboticabal, Monte Alto e Morro do Broa.

A microbacia hidrográfica do Córrego da Fazenda Glória é uma das microbacias mais importantes do município, pois está inserida na bacia do Córrego Rico e vinculada ao Comitê de Bacias do Rio Mogi-Guaçu, segundo a Divisão Hidrográfica do Estado de São Paulo.

O clima é classificado como mesotérmico úmido de verão quente (Cwa). A constituição geológica da área pertence à formação Bauru e o relevo, predominante e suave ondulado. A principal unidade de solo é classificada, de acordo com o mapa pedológico do Estado de São Paulo, segundo Oliveira et al. (1999), como Argissolos. A vegetação originária é composta pela Floresta Latifoliada Tropical.

A metodologia aplicada nesse estudo baseia-se em trabalhos disponíveis na literatura dessa área do conhecimento que foram adaptados ao material disponível e às características da área da microbacia hidrográfica. 
O estudo fundamentou-se na análise visual de fotografias aéreas verticais pertencentes ao levantamento de cobertura aerofotogramétrica realizado na região de Ribeirão Preto em 2000 pela BASE - Aerofotogrametria e Projetos S/A, com escala aproximada de 1:30.000, dimensões $23 \mathrm{~cm} \times 23 \mathrm{~cm}$, formando pares estereoscópicos, com recobrimento longitudinal aproximadamente de $60 \%$ na mesma faixa de vôo e 30\% entre as faixas adjacentes. As cartas topográficas da Coleção Cartas do Brasil, referentes a mapas originados de tomadas fotográficas aéreas de vôos realizadas na região no ano de 1964 (IBGE, 1971), foram utilizadas como material auxiliar na delimitação e decalque de diversas características da área de estudo, principalmente como ponto de apoio da rede de drenagem e da localização da microbacia hidrográfica.

Em cada fotografia, foram marcados e ligados os pontos essenciais requeridos para a montagem, sendo eles os centros principais, os centros transferidos e os pontos auxiliares, definindo as linhas radiais que serviram de guias para o ajuste das posições das fotografias. Todos os dados foram transferidos para os moldes transparentes (templetes), que são compostos pelo filme poliéster, indeformável, dificilmente afetado pelas variações da temperatura e umidade. Os detalhes deste estudo foram transferidos para o mapa base, estabelecimento da distribuição geográfica e representação geral da área.

Como resultados da interpretação visual realizada nas fotografias aéreas e nos documentos cartográficos foram identificados os seguintes geoindicadores: rede hidrográfica, os divisores topográficos, a malha viária, as áreas urbanizadas (Simões, 1997), sendo posteriormente, elaborada a carta referente à rede de drenagem da microbacia.

A carta elaborada foi georreferenciada com pontos de controle por receptores móveis e fixos GPS TRIMBLE modelo 4600 LS Geodésico, sintonizados aos satélites artificiais americanos NAVSTAR. O Marco de Referência (estação base) para a coleta dos dados com receptores GPS foi o marco geodésico do Departamento de Engenharia Rural da FCAV/UNESP, homologado no IBGE.

Para a digitalização da carta obtida, foi utilizado um software de desenho gráfico, possuindo arquivos vetoriais. Para o processamento dos dados levantados em campo e para o georreferenciamento, foi utilizado o Programa GPSurvey e, para a representação gráfica da área levantada, foi utilizado o Programa Topograph.

A caracterização das microbacias hidrográficas de $2^{\mathrm{a}}$ e $3^{\mathrm{a}}$ ordem foi efetuada mediante o emprego da análise morfométrica de cada microbacia, sendo determinadas às características dimensionais e do padrão de drenagem, determinadas conforme a seguinte metodologia:

\section{Características dimensionais}

As seguintes características dimensionais foram determinadas: área (A), perímetro $(\mathrm{P})$, maior comprimento $(\mathrm{C})$, maior largura $(\mathrm{L})$ e comprimento da rede de drenagem $(\mathrm{Cr})$ : Área (A): compreende a superfície total da bacia, medida com o planímetro em $\mathrm{km}^{2}$, (Horton, 1945);

Perímetro (P): corresponde à medida do comprimento da linha do divisor de águas da bacia, que delimita a área da mesma e foi medido com o curvímetro em km, (Smith, 1950);

Maior comprimento (C): representa a linha reta que une a foz até o ponto extremo sobre a linha do divisor de águas, seguindo a direção aproximada do vale principal, sendo medido com escalímetro em km, (Schum, 1956);

Maior Largura (L): maior dimensão linear que a bacia apresenta num eixo transversal ao vale por ela formado, sendo medido transversalmente ao maior comprimento com escalímetro em km, (Strahler, 1957); 
Comprimento da rede de drenagem $(\mathrm{Cr})$ : corresponde ao comprimento total do segmento de rio que forma a rede de drenagem da bacia hidrográfica, sendo medido pelo curvímetro em km, (Horton, 1945).

Para caracterizar o comprimento da rede de drenagem em cada microbacia, consideraram-se tanto os rios perenes como os canais intermitentes. Segundo Christofoletti (1970), considerando-se apenas rios perenes, o resultado seria maior em relação à precipitação pluviométrica elevada no decorrer do ano. Omitindo-se os canais intermitentes, nas regiões secas, não haveria possibilidade de se medir o comprimento da rede de drenagem e os cálculos seriam nulos. Nas regiões de clima mais seco, apesar da rede de drenagem ser, em geral, formada por canais intermitentes, há toda uma hierarquia hidrográfica.

\section{Características da composição da rede de drenagem}

As características da composição da rede de drenagem são definidas a seguir:

Número de segmentos de rios de $1^{\mathrm{a}}$ ordem (Nw1): representa a quantidade de segmentos de rios de $1^{\mathrm{a}}$ ordem (Horton, 1945).

Número de segmentos de rios de $2^{\mathrm{a}}$ ordem (Nw2): representa a quantidade de segmentos de rios de $2^{\mathrm{a}}$ ordem (Horton, 1945).

Número de segmentos de rios de $3^{\mathrm{a}}$ ordem (Nw3): representa a quantidade de segmentos de rios de $3^{\mathrm{a}}$ ordem (Horton, 1945).

Número de segmentos de rios de $4^{\text {a }}$ ordem (Nw4): representa a quantidade de segmentos de rios de $4^{\mathrm{a}}$ ordem (Horton, 1945).

Comprimento total de rios de $1^{\text {a }}$ ordem (Ctw1): corresponde ao comprimento total de todos os segmentos de rio de $1^{\text {a }}$ ordem que forma a rede de drenagem da bacia hidrográfica, sendo medido com curvímetro em km, (Horton, 1945).

Comprimento total de rios de $\mathbf{2}^{\mathrm{a}}$ ordem (Ctw2): corresponde ao comprimento total de todos os segmentos de rio de $2^{\mathrm{a}}$ ordem que forma a rede de drenagem da bacia hidrográfica, sendo medido pelo curvímetro em km, (Horton, 1945).

Comprimento total de rios de $3^{\text {a }}$ ordem (Ctw3): corresponde ao comprimento total de todos os segmentos de rio de $3^{\mathrm{a}}$ ordem que forma a rede de drenagem da bacia hidrográfica, sendo medido pelo curvímetro em km, (Horton, 1945).

Comprimento total de rios de $4^{\text {a }}$ ordem (Ctw4): corresponde ao comprimento total de todos os segmentos de rio de $4^{\mathrm{a}}$ ordem que forma a rede de drenagem da bacia hidrográfica, sendo medido pelo curvímetro em km, (Horton, 1945).

\section{RESULTADOS E DISCUSSÕES}

As características morfométricas quantitativas das microbacias de $2^{\mathrm{a}}$ e $3^{\mathrm{a}}$ ordens de magnitude ocorrentes na microbacia hidrográfica do Córrego da Fazenda Glória (Figura 1) foram classificadas de acordo com Strahler (1957). 

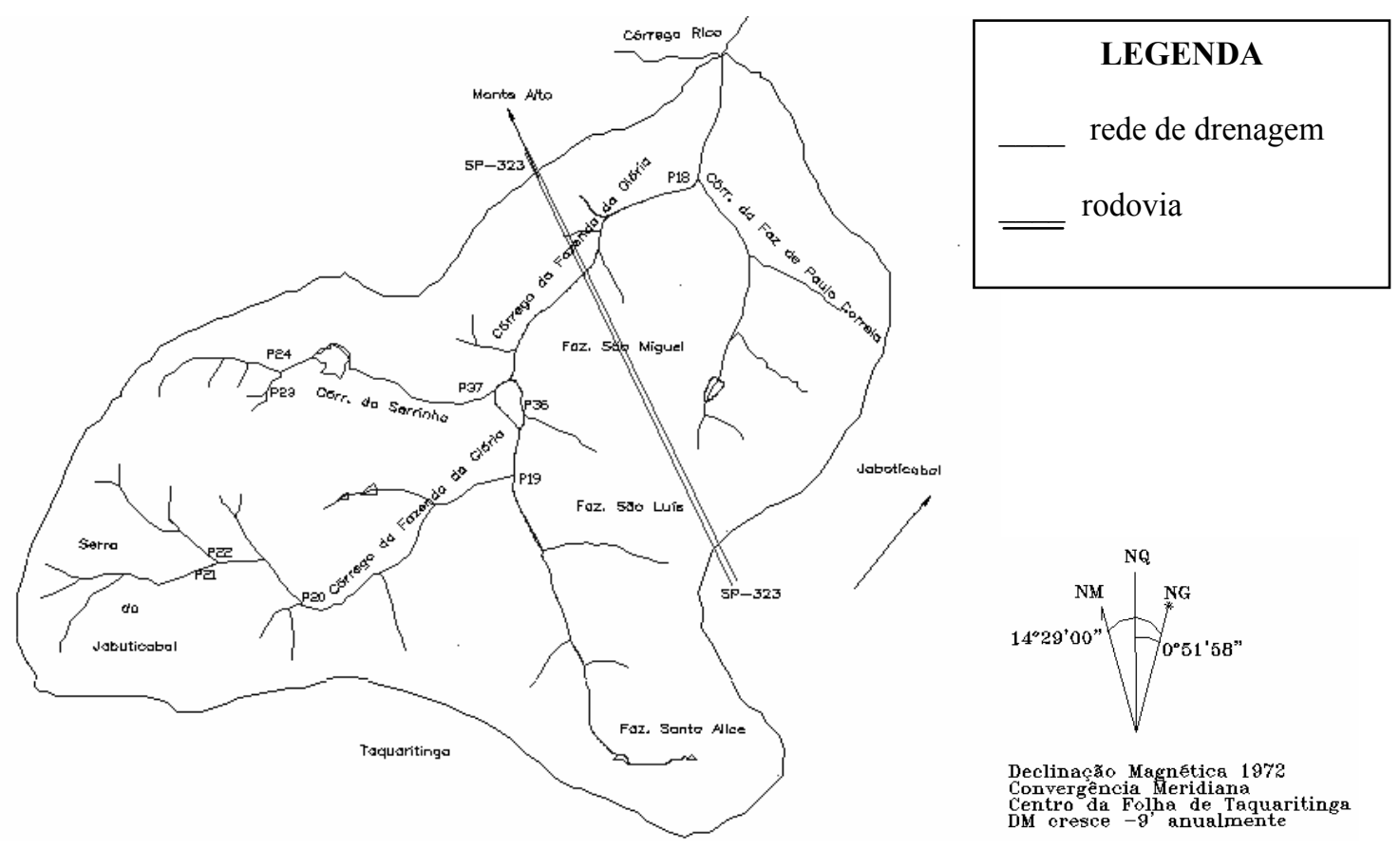

Figura 1. Carta da localização das microbacias de $2^{\mathrm{a}}$ e $3^{\mathrm{a}}$ ordens de magnitude que pertencem a microbacia hidrográfica do Córrego da Fazenda Glória, Taquaritinga, SP.

Os dados (Tabela 1) baseados nas fotografias aéreas de 2000 foram comparados com os dados do período de 1983, apresentado por Pissarra (2002).

Os valores médios das características dimensionais (Tabelas 1 e 2) apresentaram variabilidade média a alta, mantendo um comportamento semelhante ao observado por Pissarra (2002).

A área da microbacia, característica determinante para a totalização do escoamento superficial das águas das chuvas, mostra que a microbacia P23 apresentou a menor área $\left(208250 \mathrm{~m}^{2}\right)$ e a P19 apresentou a maior área $\left(41098750 \mathrm{~m}^{2}\right)$, indicando maior escoamento total. Esses resultados estão em consonância com os trabalhos desenvolvidos por Pissarra (2002), provavelmente, tendo em vista que a microbacia P19 apresenta-se na área limítrofe entre os Argissolos e Latossolos.

Este fato reflete na permeabilidade e na relação infiltração/deflúvio, concordando com trabalhos desenvolvidos por Politano (1992); Demattë \& Demétrio (1996); Silva (1999) e Pissarra (2002). Esta relação influencia a espessura, textura, agregação e estrutura do solo, sendo possível observar a diferença na área estudada entre as microbacias.

Pode-se verificar nas duas microbacias hidrográficas de $3^{\mathrm{a}}$ ordem de magnitude que houve um decréscimo do comprimento da rede de drenagem, em aproximadamente $23,2 \%$, apresentando uma variabilidade média de 0,76 em 1983 e 0,96 em 2000 . No conjunto de dados apresentados, evidencia-se que as características dimensionais do comprimento da rede de drenagem das microbacias foram as únicas que sofreram modificações no período analisado. Essas diferenças podem estar relacionadas às diversas influências da atividade antrópica, ocasionando o comportamento hidrológico desigual. 
Tabela 1. Valores das características dimensionais das microbacias hidrográficas de $2^{\mathrm{a}}$ ordem de magnitude no período de 1983 e 2000, da microbacia hidrográfica do Córrego da Fazenda Glória, Taquaritinga - SP.

\begin{tabular}{|c|c|c|c|c|c|}
\hline \multirow{2}{*}{$\begin{array}{c}\text { Microbacia } \\
2^{\mathrm{a}} \text { ordem }\end{array}$} & \multicolumn{5}{|c|}{ Características Dimensionais - 1983} \\
\hline & $A\left(m^{2}\right)$ & $\mathbf{P}(\mathbf{m})$ & $\mathbf{C}(\mathbf{m})$ & L (m) & $\operatorname{Cr}(\mathrm{m})$ \\
\hline P18 & 3215625 & 7245 & 2660 & 1592,5 & 4042,5 \\
\hline P19 & 4109875 & 8400 & 2940 & 2397,5 & 4865,0 \\
\hline $\mathrm{P} 20$ & 937125 & 4725 & 1890 & 665 & 962,5 \\
\hline $\mathrm{P} 21$ & 1163750 & 4602,5 & 1610 & 1260 & 2100,0 \\
\hline $\mathrm{P} 22$ & 1078000 & 4585 & 1470 & 1085 & 2012,5 \\
\hline $\mathrm{P} 23$ & 208250 & 1820 & 770 & 315 & 752,5 \\
\hline $\mathrm{P} 24$ & 618625 & 3640 & 1505 & 752,5 & 1312,5 \\
\hline Total & 11331250 & 35017,5 & 12845 & 8067,5 & 16047,5 \\
\hline Média & 1618750 & 5002,5 & 1835 & 1152,5 & 2292,5 \\
\hline CV (\%) & 0,90 & 0,44 & 0,41 & 0,60 & 0,69 \\
\hline Microbacia & \multicolumn{5}{|c|}{ Características Dimensionais - 2000} \\
\hline $2^{\mathrm{a}}$ ordem & $A\left(m^{2}\right)$ & $\mathbf{P}(\mathbf{m})$ & $\mathbf{C}(\mathbf{m})$ & $\mathbf{L}(\mathbf{m})$ & $\operatorname{Cr}(\mathrm{m})$ \\
\hline P18 & 3215625 & 7245 & 2660 & 1592,5 & 3450,0 \\
\hline P19 & 4109875 & 8400 & 2940 & 2397,5 & 4305,0 \\
\hline $\mathrm{P} 20$ & 937125 & 4725 & 1890 & 665 & 480,0 \\
\hline $\mathrm{P} 21$ & 1163750 & 4602,5 & 1610 & 1260 & 2565,0 \\
\hline P22 & 1078000 & 4585 & 1470 & 1085 & 1695,0 \\
\hline $\mathrm{P} 23$ & 208250 & 1820 & 770 & 315 & 675,0 \\
\hline $\mathrm{P} 24$ & 618625 & 3640 & 1505 & 752,5 & 1170,0 \\
\hline Total & 11331250 & 35017,5 & 12845 & 8067,5 & 14340,0 \\
\hline Média & 1618750 & 5002,5 & 1835 & 1152,5 & 2048,6 \\
\hline CV (\%) & 0,90 & 0,44 & 0,41 & 0,60 & 0,71 \\
\hline
\end{tabular}

Tabela 2. Valores das características dimensionais das microbacias hidrográficas de $3^{\mathrm{a}}$ ordem de magnitude no período de 1983 e 2000, da microbacia hidrográfica do Córrego da Glória, Município de Taquaritinga - SP.

\begin{tabular}{cccccc}
\hline $\begin{array}{c}\text { Microbacia } \\
\mathbf{3}^{\mathbf{a}} \text { ordem }\end{array}$ & \multicolumn{5}{c}{ Características Dimensionais - 1983 } \\
\cline { 2 - 6 } & $\mathbf{A ~ ( \mathbf { m } ^ { \mathbf { 2 } } )}$ & $\mathbf{P}(\mathbf{m})$ & $\mathbf{C}(\mathbf{m})$ & $\mathbf{L}(\mathbf{m})$ & $\mathbf{C r}(\mathbf{m})$ \\
\hline P36 & 10910000 & 15750 & 2420 & 5710 & 16100 \\
\hline P37 & 2310000 & 6830 & 3010 & 1240 & 4830 \\
\hline Total & 13220000 & 22580 & 5430 & 6950 & 20930 \\
\hline Média & 6610000 & 11290 & 2715 & 3475 & 10465 \\
\hline $\mathbf{C V ~ ( \% ) ~}$ & 0,92 & 0,56 & 0,15 & 0,91 & 0,76 \\
\hline $\begin{array}{c}\text { Microbacia } \\
\mathbf{3}^{\mathbf{a}} \text { ordem }\end{array}$ & $\mathbf{A}\left(\mathbf{m}^{\mathbf{2}}\right)$ & $\mathbf{P}(\mathbf{m})$ & $\mathbf{C}(\mathbf{m})$ & $\mathbf{L}(\mathbf{m})$ & $\mathbf{C r} \mathbf{( m )}$ \\
\hline P36 & 10910000 & 15750 & 2420 & 5710 & 13470 \\
\hline P37 & 2310000 & 6830 & 3010 & 1240 & 2610 \\
\hline Total & 13220000 & 22580 & 5430 & 6950 & 16080 \\
\hline Média & 6610000 & 11290 & 2715 & 3475 & 8040 \\
\hline CV (\%) & 0,92 & 0,56 & 0,15 & 0,91 & 0,96
\end{tabular}


No conjunto de dados apresentados, evidencia-se que as características dimensionais do comprimento da rede de drenagem das microbacias foram às únicas que sofreram modificações no período analisado. Essas diferenças podem estar relacionadas às diversas influências da atividade antrópica, ocasionando comportamento hidrológico desigual.

Os comprimentos dos canais (Figura 2) apresentaram-se menores em quase todas as microbacias, exceto na microbacia P21. Salienta-se que, em visitas técnicas em campo, observa-se que a nascente desta rede de drenagem foi represada e, ao redor, realizaram um reflorestamento com espécies vegetais nativas, possivelmente sendo esta a causa da conservação do comprimento da rede de drenagem durante o período.

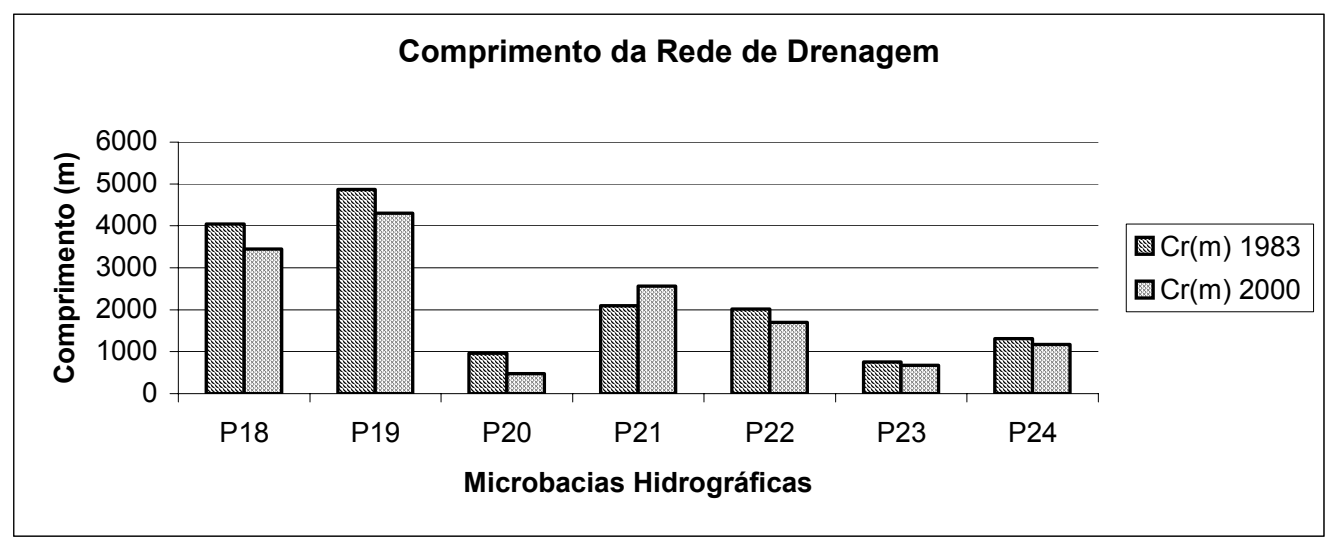

Figura 2. Comprimento dos canais de drenagem de $2 .^{\mathrm{a}}$ ordem da microbacia hidrográfica Córrego da Fazenda da Glória, Taquaritinga - SP de 1983 a 2000.
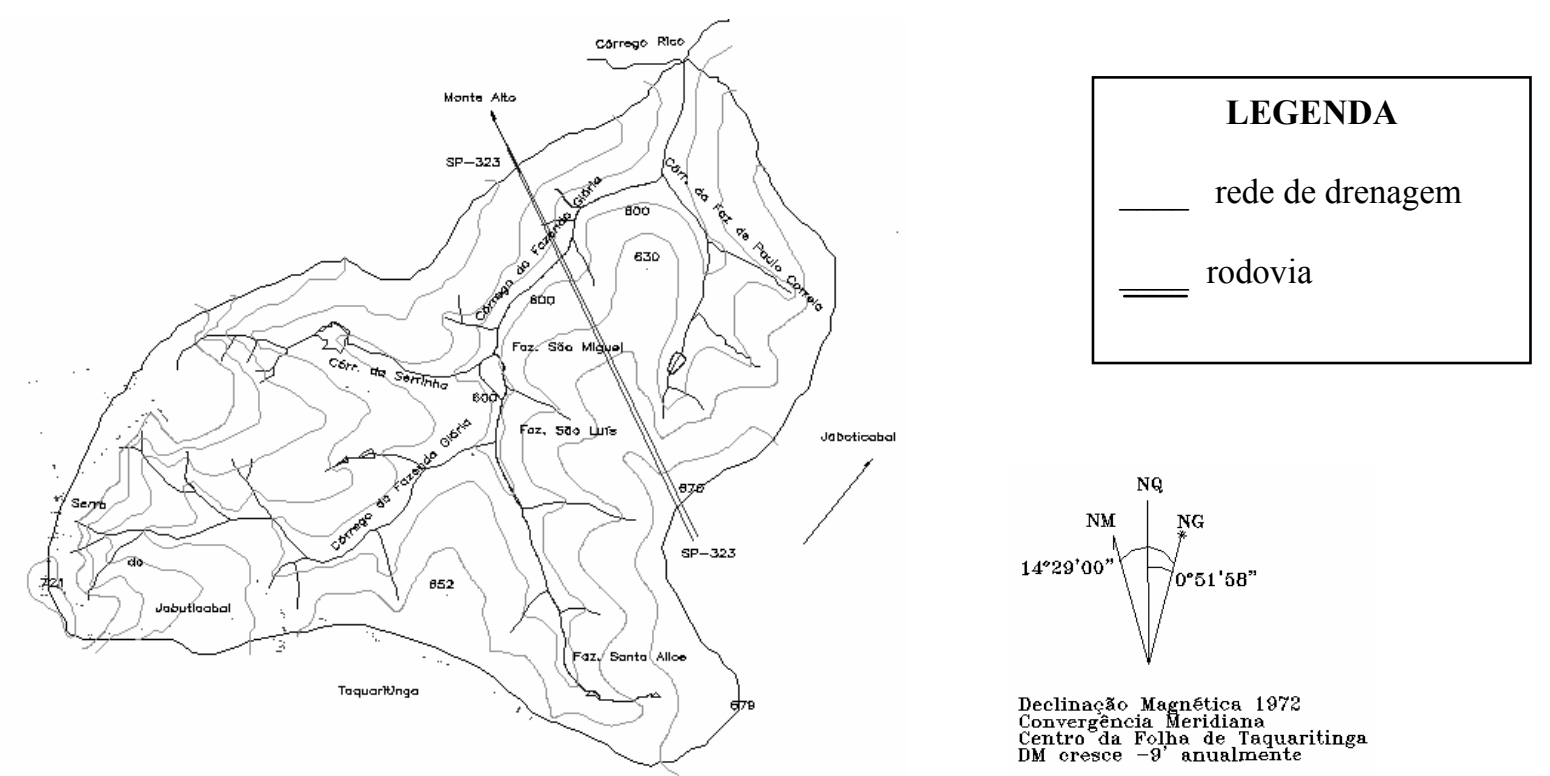

Figura 3. Carta planialtimétrica da microbacia hidrográfica do Córrego da Fazenda Glória, Taquaritinga, SP.

Considerando a soma do comprimento da rede de drenagem, ocorreu uma diferença de $16047,5 \mathrm{~m}$ para $14340 \mathrm{~m}$ no período, o que influencia diretamente na água superficial, pois quanto maior o valor, implica-se em maior água acumulada no canal escoadouro (Strahler, 1957). Essas diferenças podem estar relacionadas às diversas influências que a evolução do 
modelado sofreu, indicando comportamento hidrológico desigual, semelhante ao observado por Pissarra (2002) e Borges (2005).

Observa-se, na carta planialtimétrica (Figura 3), que a rede de drenagem nas microbacias dos Córregos da Serrinha e da Fazenda Glória (oeste da microbacia), os fatores ligados aos controles estruturais e topográficos exercem, em parte, efeitos distintos ligados às posições dos cursos d'água no sistema de drenagem. A microbacia do Córrego da Fazenda Santa Alice (P19) apresenta-se com o comprimento menor em $560 \mathrm{~m}$. Essa variação pode ocorrer tendo em vista as alterações edáficas provocadas pelos diferentes sistemas de preparo do solo no manejo das culturas, fato observado claramente nas visitas técnicas em campo.

Tabela 3. Valores das características da composição da rede de drenagem das microbacias hidrográficas de $2^{\mathrm{a}}$ ordem de magnitude no período de 1983 e 2000 , da microbacia hidrográfica do Córrego da Glória, Município de Taquaritinga - SP.

\begin{tabular}{|c|c|c|c|c|c|c|c|c|c|c|c|}
\hline \multicolumn{6}{|c|}{1983} & \multicolumn{6}{|c|}{2000} \\
\hline $\begin{array}{c}\text { Número } \\
2^{\mathrm{a}} \\
\text { Ordem }\end{array}$ & Nw1 & Nw2 & Total & $\begin{array}{c}\text { Ctw1 } \\
\text { (m) }\end{array}$ & $\begin{array}{c}\text { Ctw2 } \\
\text { (m) }\end{array}$ & $\begin{array}{c}\text { Número } \\
2^{\mathrm{a}} \\
\text { Ordem }\end{array}$ & Nw1 & Nw2 & Total & Ctw1 & Ctw2 \\
\hline $\mathrm{P} 18$ & 4 & 1 & 5 & 2065,00 & 1977,50 & P18 & 3 & 1 & 4 & 1605 & 1845 \\
\hline P19 & 4 & 1 & 5 & 3465,00 & 1400,00 & P19 & 4 & 1 & 5 & 2805 & 1500 \\
\hline P20 & 2 & 1 & 3 & 770,00 & 192,50 & P20 & 2 & 1 & 3 & 330 & 150 \\
\hline $\mathrm{P} 21$ & 3 & 1 & 4 & 980,00 & 1120,00 & $\mathrm{P} 21$ & 3 & 1 & 4 & 1455 & 1110 \\
\hline $\mathrm{P} 22$ & 3 & 1 & 4 & 1015,00 & 997,00 & P22 & 3 & 1 & 4 & 795 & 900 \\
\hline $\mathrm{P} 23$ & 3 & 1 & 4 & 472,50 & 280,00 & P23 & 3 & 1 & 4 & 375 & 300 \\
\hline $\mathrm{P} 24$ & 3 & 1 & 4 & 840,00 & 472,00 & P24 & 3 & 1 & 4 & 720 & 450 \\
\hline TOTAL & 22 & 8 & 29 & 9607,00 & 6440,00 & TOTAL & 21 & 8 & 28 & 8085 & 6255 \\
\hline
\end{tabular}

$\mathrm{Na}$ análise geral da microbacia hidrográfica do Córrego da Fazenda da Glória, o comprimento do segmento de rio de $4^{\mathrm{a}}$ ordem se manteve constante ao longo do período analisado.

Os valores do comprimento dos canais de drenagem de 2. ${ }^{a}$ ordem (Ctw2), Tabelas 2 e 3 , apresentaram-se semelhantes ao longo dos anos, indicando maior controle estrutural no desenvolvimento dos rios de $2^{\mathrm{a}}$ ordem de magnitude, determinando uma composição da drenagem e desenvolvimento fisiográfico praticamente inalterado nas microbacias na área estudada.

Tabela 4. Valores das características da composição da rede de drenagem das microbacias hidrográficas de $3^{\mathrm{a}}$ ordem de magnitude no período de 1983 e 2000 , da microbacia hidrográfica do Córrego da Glória, Município de Taquaritinga - SP.

\begin{tabular}{|c|c|c|c|c|c|c|c|}
\hline Período & \multicolumn{7}{|c|}{1983} \\
\hline Microbacia & Nw1 & Nw2 & Nw3 & Total & Ctw1 m) & Ctw2 (m) & Ctw3 (m) \\
\hline P36 & 15 & 4 & 1 & 20 & 8890,00 & 4760,00 & 2450,00 \\
\hline P37 & 8 & 2 & 1 & 11 & 2432,50 & 752,50 & 1645,00 \\
\hline Total & $\mathbf{2 3}$ & $\mathbf{6}$ & $\mathbf{2}$ & $\mathbf{3 1}$ & $\mathbf{1 1 3 2 2 , 0 0}$ & $\mathbf{5 5 1 2 , 5 0}$ & $\mathbf{4 0 9 5 , 0 0}$ \\
\hline & \multicolumn{7}{|c|}{$\mathbf{2 0 0 0}$} \\
\hline P36 & 16 & 4 & 1 & 21 & 7140,00 & 3855,00 & 2475,00 \\
\hline P37 & 5 & 2 & 1 & 8 & 870,00 & 450,00 & 1290,00 \\
\hline Total & $\mathbf{2 1}$ & $\mathbf{6}$ & $\mathbf{2}$ & $\mathbf{3 1}$ & $\mathbf{8 0 1 0 , 0 0}$ & $\mathbf{4 3 0 5 , 0 0}$ & $\mathbf{3 7 6 5 , 0 0}$ \\
\hline
\end{tabular}


De modo geral, estes dados são mais estáveis que as características dimensionais, não diferindo no período analisado, semelhante aos resultados encontrados por Silva (1999).

Os dados (Tabela 4) permitem verificar uma redução na quantidade de segmentos de rios de $1^{\text {a }}$ ordem de magnitude na microbacia hidrográfica P37 e, ao longo do período analisado, e uma notável diminuição do comprimento dos segmentos de rios de $2^{\mathrm{a}}$ e $3^{\mathrm{a}}$ ordem de magnitude.

O relevo (Figura 3) evolui de suave ondulado (bacia do córrego da Faz. de Paulo Correia e Faz. Santa Alice) para ondulado (Córrego da Serrinha e da Faz. da Glória) e, os valores médios da densidade de drenagem $(\mathrm{Dd}=1,84)$, freqüência de rios $(\mathrm{F}=5,54)$ e razão de textura $(T=0,99)$ foram semelhantes aos obtidos por Pissarra $(2002)$, refletindo num mesmo ambiente climático, onde a infiltração da água encontra maior dificuldade, melhores condições para escoamento intenso superficial, causando, consequentemente, maior esculturação hídrica do terreno à montante da microbacia na direção da Serra do Jabuticabal, concordando com observações de Campos et al. (1993); Pissarra (1998 e 2002) e Silva (1999), entre outros pesquisadores.

Os valores da densidade de drenagem (Dd) foram maiores nas microbacias do Córrego da Serrinha e na Serra do Jabuticabal, provavelmente devido ao relevo mais forte e maior declividade da área. Geralmente, os valores de Dd aumentam e o tamanho individual de cada rede de drenagem diminui, proporcionalmente, sendo menor o tamanho das bacias e maior o número de canais dentro de cada bacia.

Esses valores são considerados de importância primária na análise da paisagem geomorfológica em bacias hidrográficas (Rocha, 1991). Indicam uma mudança morfológica que é esperada quando a resistência da superfície é baixa, sendo um indicativo para o devido uso da terra.

Quanto maior os valores médios de Dd, F e T, mais intenso é o processo erosivo. Nas bacias hidrográficas inseridas nos Argissolos o processo de esculturação do relevo é mais proeminente, dada a baixa resistência desses solos à erosão, mostrando diferentes texturas topográficas que se apresentam em conformidade com o tipo de solo, refletindo distintas condições de relevo ondulado a suave ondulado (Figura 3).

Os valores da média das características do relevo amplitude altimétrica $(\mathrm{H}=80,57)$, razão de relevo $(\mathrm{Rr}=50,32)$, razão de relevo relativo $(\mathrm{Rrl}=19,04)$, coeficiente de rugosidade $(\mathrm{RN}=26,35)$ e declividade média da bacia $(\mathrm{DMBac}=12,72)$, demonstram aspectos relacionados com o grau de desnível existente entre o divisor topográfico e respectivos talvegues, e extensão e grau de declive das encostas.

Essas características indicam a proporção na qual o processo erosivo se desencadeia, visto que, descrevem fenômenos relacionados ao desenvolvimento da topografia e conformação das bacias hidrográficas. E apresentam o grau de evolução da microbacia hidrográfica, onde as bacias de cabeceiras apresentam transporte do material em maior escala, tendendo a menor resistência à remoção do manto superficial, com indícios de processo erosivo mais intenso. Esse fato foi muito bem observado nos trabalhos em campo.

A complexidade encontrada é agravada nas microbacia da Fazenda Santa Alice, onde a degradação da rede de drenagem e do solo, gerada pelo manejo inadequado do solo, carreadores e estradas rurais, favorece o escoamento de enxurradas das águas provenientes da chuva, afetando drasticamente a qualidade ambiental, representada pela degradação do solo e poluição da água.

Este fato ocasionou o desenvolvimento de um trabalho de análise da água, o qual está sendo desenvolvido no Departamento de Engenharia Rural, pelos Professores João Antônio 
Galbiatti e Teresa Cristina Tarlé Pissarra. Os dados observados em campo estiveram diretamente relacionados com os dados obtidos da interpretação visual nas imagens fotográficas. As condições da evolução e uso/ocupação da microbacia hidrográfica estão diretamente relacionadas com o grau de movimentação topográfica e características da rede de drenagem, refletindo, portanto, condições importantes do meio relacionadas com o desenvolvimento agronômico e a preservação ambiental.

Ressalta-se, ainda, que o estudo geomorfológico de uma região estaria incompleto sem o estudo do relevo, visto que este é o fator condicionante para inúmeros outros elementos da paisagem tais como a vegetação e a hidrografia; além disso, é fator determinante para inúmeras atividades econômicas ligadas à exploração de recursos naturais.

\section{CONCLUSÕES}

As características morfométricas demonstraram que ocorreu uma redução do número de segmentos de rios de 1. ${ }^{\mathrm{a}}$ ordem e comprimento da rede de drenagem ao longo do período analisado, o que influencia diretamente na água superficial, estando relacionadas às diversas influências que a evolução sofreu, indicando comportamento hidrológico desigual.

$\mathrm{Na}$ análise geral da microbacia hidrográfica do Córrego da Fazenda Glória, o comprimento do segmento de rio de $4^{\mathrm{a}}$ ordem se manteve constante ao longo do período.

A análise morfométrica na microbacia hidrográfica contribuiu para a compreensão do sistema de drenagem e do relevo, através de parâmetros que consistiram em levantamentos de índices, relações e valores numéricos. Esses parâmetros definiram a natureza dos sistemas, permitiram uma análise integrada de dados, estabelecendo relação entre os processos e a morfologia resultante.

\section{REFERÊNCIAS BIBLIOGRÁFICAS}

ALVES, J. M. P.; CASTRO, PTA. Influência de feições geológicas na morfologia da bacia do rio Tanque (MG) baseada no estudo de parâmetros morfométricos e análise de padrões de lineamentos. Revista Brasileira de Geociências, João Pessoa - PB, v. 33, n. 2, p. 117-127, 2003.

BORGES, M. J. Diagnóstico físico conservacionista na determinação do reflorestamento compensatório para retenção de água em microbacias hidrográficas. $120 \mathrm{f}$. Tese (Doutorado em Geoprocessamento) - Faculdade de Ciências Agrárias e Veterinárias, Universidade Estadual Paulista, Jaboticabal, 2005.

CAMPOS, S. et al. Índice quantitativos do padrão de drenagem, obtidos por meio de interpretação de imagens TM/LANDSAT-5, na caracterização de unidades de solo no município de Piracicaba-SP. In: CONGRESSO BRASILEIRO DE ENGENHARIA AGRÍCOLA, 22, 1993, Ilhéus. Anais... Ilhéus: Sociedade Brasileira de Engenharia Agrícola, 1993, v. 5, p. 430-39.

CARDOSO, CA et al. Caracterização morfométrica da bacia hidrográfica do rio Debossan, Nova Friburgo, RJ. Revista Árvore, Viçosa, v. 30, n. 2, 2006. 
CHRISTOFOLETTI, A. Análise morfométrica de bacias hidrográficas no Planalto de Poços de Caldas. 1970. 375 f. Tese (Livre Docência) - Universidade Estadual Paulista, Rio Claro, 1970.

Morfologia de bacias de drenagem. Notícias Geomorfológicas, Campinas, v. 18, n. 36, (p. 130-132), 1978.

Morfologia do relevo na média Bacia do rio Corumbataí. In: SIMPÓSIO DE GEOGRAFIA FÍSICA APLICADA, 5, 1993, São Paulo: Anais... Rio de Janeiro: Sociedade Brasileira de Geografia Física Aplicada, 1993.

DEMATTÊ, J. A. M.; DEMÉTRIO, V. A. Padrões de drenagem em áreas de solos desenvolvidos de rochas vulcânicas ácidas na região de Guarapuava. Revista Brasileira Ciência do Solo, Campinas, v. 20, (p. 305-11), 1996.

FRANÇA, G. V. Interpretação fotográfica de bacias e redes de drenagem aplicadas a solos da região do Piracicaba. $151 \mathrm{f}$. Tese (Doutorado em Agronomia) - Escola Superior de Agricultura Luiz de Queiróz, Universidade de São Paulo, Piracicaba, 2005.

GUERRA, A. T.; GUERRA, AJT. Novo dicionário geológico-geomorfológico. 3 ed. Rio de Janeiro: Bertrand Brasil, 2003. 652 p.

HORTON, R. E. Erosional development of streams and their drainage basins: hidrophysical approach to quantitative morphology. Bulletin of the Geological Society of American, Colorado, v. 56, n. 3, 1945.

INSTITUTO BRASILEIRO DE GEOGRAFIA E ESTASTÍSTICA. Departamento de Cartografia. Carta do Brasil: Jaboticabal e Taquaritinga. São Paulo, 1971. Escala 1:50000.

LIMA, W. P. Princípios de hidrologia florestal para o manejo de bacias hidrográficas. São Paulo: USP, Escola Superior de Agricultura Luiz de Queiroz, 1986. 242 p.

OLIVEIRA, J. B. et al. Mapa pedológico do Estado de São Paulo. Empresa Brasileira de Pesquisa Agropecuária, Campinas, 1999. 64p.

PISSARRA,T. C. T. Análise da bacia hidrográfica do Córrego Rico na sub-região de Jaboticabal, SP: comparação entre imagens TM-LANSAT 5 e fotografias aéreas verticais. 132 f. Dissertação (Doutorado em Conservação e Manejo da Água e do Solo) Faculdade de Ciências Agrárias e Veterinárias, Universidade Estadual Paulista, Jaboticabal, 2002.

PISSARRA, T. C. T. Avaliação quantitativa das características geomórficas de microbacia hidrográficas de $1^{a}$ Ordem de magnitude em quatro posições do sistema de drenagem. 124 f. Dissertação (Mestrado em Conservação e Manejo da Água e do Solo) Faculdade de Ciências Agrárias e Veterinárias, Universidade Estadual Paulista, Jaboticabal, 1998. 
POLITANO, W. Estudo da adequabilidade do emprego de bacias hidrográficas de $3^{\mathbf{a}}, \mathbf{2}^{\mathbf{a}}$, $1^{\mathrm{a}}$ ordem de magnitude na análise morfométrica aplicada a solos. $331 \mathrm{f}$. Tese (LivreDocência em Topografia e Fotogrametria) - Faculdade de Ciências Agrárias e Veterinárias, Universidade Estadual Paulista, Jaboticabal, 1992.

ROCHA, J. S. M. Manual de manejo integrado de bacias hidrográficas. Santa Maria, UFSM, 1991.

SILVA, H. R. Influência da posição da microbacia hidrográfica de $2^{a}$ ordem de magnitude no sistema natural de drenagem sobre a variabilidade das suas características morfométricas. $186 \mathrm{f}$. Tese (Doutorado em Agronomia) - Faculdade de Ciências Agrárias e Veterinárias, Universidade Estadual Paulista, Jaboticabal, 1999.

SIMÕES, S. J. C. A dinâmica dos sistemas e a caracterização de geoindicadores. In: MAIA, NB.; LESJAK, H. Indicadores ambientais. Sorocaba: Bandeirantes, 1997. p. 59-70.

SCHUMM, S. A. Evolution of drainage systems and slopes in bedlands at Perth Amboy. Bulletin of the Geological Society of American, New Jersey, v. 67, p. 597-646, 1956.

SMITH, K. G. Standards for grading texture of erosional topography. American Journal Science, v.248, p. 655-68, 1950.

STRAHLER, A. N. Quantitative analysis of watershed geomorphology. Transform. American Geophysical, New Haven, v. 38, 1957, p. 913-20. 